\title{
The effect of leader damage on lodgepole pine site tree height growth
}

\author{
by Gord Nigh ${ }^{1}$
}

\begin{abstract}
Site index is an important parameter in forest management. Selecting good site trees is critical for both developing and applying models to estimate site index. Along with other characteristics, site trees must be free of damage so that the growth of the tree reflects the potential productivity of the site. Detecting and avoiding leader damage in site trees is very difficult because radial stem growth eventually hides the damage, even in young trees. This project quantifies the loss in height growth due to hidden leader damage. Thirty-seven lodgepole pine (Pinus contorta var. latifolia) site trees were destructively sampled. Annual height growth was measured and incidents of leader damage noted. Height growth was modelled in a mixed-effects framework and allowed for growth reductions due to leader damage. Height growth was reduced on average by $35 \%$ in the year the damage occurred and by $15 \%$ in the year after the damage event. Height growth returned to normal in subsequent years. The effect of leader damage on the estimated site index depends on when and how many damage events occur, and when the site index estimate is made. For a tree with a site index of $20 \mathrm{~m}$ at base age 50 years at breast height that has leader damage at age 8 , a reduction in the estimated site index of $0.59 \mathrm{~m}$ and $0.31 \mathrm{~m}$ can be expected when site index is estimated at ages 10 and 25 , respectively.
\end{abstract}

Keywords: lodgepole pine; leader damage; height growth; site index; stem analysis

\section{RÉSUMÉ}

L'indice de qualité de station est un paramètre important en aménagement forestier. Il importe donc de choisir des arbres adaptés au site (site trees) pour élaborer des modèles destimation de l'indice de qualité de station et pour les utiliser. Comme pour les autres variables, les arbres adaptés doivent être exempts de défaut afin que leur croissance reflète bien toute la productivité de la station. Il est très difficile de déceler et déviter les dommages à la flèche terminale chez les arbres adaptés parce que la croissance radiale finit par masquer ce dommage, même sur de jeunes arbres. Ce projet avait pour but de quantifier les pertes de croissance en hauteur attribuables aux dommages cachés à la flèche terminale. Trente-sept pins tordus (Pinus contorta var. latifolia) adaptés à la station ont fait lobjet de tests destructifs. On en a mesuré la croissance annuelle en hauteur en plus de noter la présence de dommage à la flèche terminale. On a ensuite utilisé un modèle mixte pour modéliser la croissance en hauteur en tenant compte de la réduction de croissance résultant du dommage relevé sur la flèche terminale. En moyenne, la croissance en hauteur a été réduite de $35 \%$ l’année du dommage et de $15 \%$ l'année suivante. La croissance en hauteur est revenue à la normale dans les années qui suivirent. Leffet du dommage à la flèche terminale sur lestimation de l'indice de qualité de station dépend du moment où il se produit et du nombre de sites affectés ainsi que du moment où l'on estime l'indice de qualité de station. Pour un arbre dont l'indice de qualité de station affiche $20 \mathrm{~m}$ à 50 ans au dhp et qui présentait un dommage à la flèche terminale à lâge de 8 ans, on peut envisager une diminution de l'indice de qualité de station de 0,59 $\mathrm{m}$ et de 0,31 m lorsque cet indice est estimé à 10 ans et 25 ans respectivement.

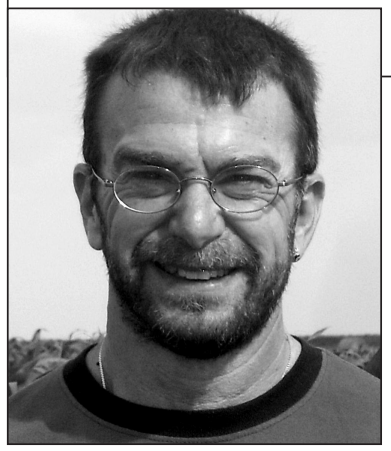

Mots clés : pin tordu, dommage à la flèche terminale, croissance en hauteur, indice de la qualité de station, analyse de la tige

Gord Nigh

\footnotetext{
${ }_{1}^{1}$ Forest Analysis and Inventory Branch, B.C. Ministry of Forests, Lands and Natural Resource Operations, Victoria, B.C., Canada V8W 9C2 email: Gordon.Nigh@gov.bc.ca
} 


\section{Introduction}

Site index is a measure of site productivity which is usually regarded as the potential to produce wood (Skovsgaard and Vanclay 2008). Its use in forest management is almost universal. "Site index is often assumed to be the 'true' current or potential volume production" and is "an unquestionable cornerstone in our comprehension of forest growth" (Skovsgaard and Vanclay 2008). Since the growth and yield of timber in a stand is related to site productivity, site index is often one of the most critical variables in growth and yield models used in forest management to plan silviculture treatments and in timber supply analyses to set allowable annual harvest levels. These fundamental forest management applications are what makes site index such an important parameter for forest practitioners.

Site index is, in a general way, defined as height at a reference (index) age (Bontemps and Bouriaud 2014). Trees that are selected for site index estimation are referred to as site or top height trees. It is generally recognized that the site trees should be free-growing, undamaged, free from insect and disease attack, and be dominant and/or co-dominant in order for the trees to express the potential of the site (Carmean 1975, Monserud 1984, 1985; Green et al. 1989, Krumland and Eng 2005). However, this assumption is not always explicit (e.g., Carvalho and Parresol 2005, Nord-Larsen 2006). When the site trees are not at the index age, models are used to predict site index from species, site tree height, age, and perhaps other variables. Site trees are required to both develop and to apply the models. The criteria for selecting site trees for model development and application must be the same or biases in site index may result (Monserud 1984).

For conifer species with determinate growth, such as lodgepole pine (Pinus contorta Dougl. ex Loud. var. latifolia Engelm), a terminal bud is set every year which determines the stem unit of the following year. A scar is left in the pith where the terminal bud has set which is called a pith node (Niklasson 2002). Accurate data for site index research is obtained by splitting open the stem to identify and measure the height of the pith nodes. However this sampling procedure often reveals a surprisingly large amount of leader damage that was hidden by subsequent radial growth of the stem (Nigh and Love 1999). This type of stem analysis data provides the opportunity to examine how much loss in height growth, if any, is realized by leader damage. This loss in height growth will subsequently result in lower site indexes.

This research extends the work of Nigh and Love (1999) by quantifying the amount of height growth loss in lodgepole pine that occurs due to leader damage that has been hidden by radial stem growth. Two hypotheses are proposed: the reduction in height growth (if any) due to damage is shortlived and height growth rates return to normal; and, height growth is reduced after damage and accumulates as more damage events occur.

\section{Data}

Data for this study were collected in the Merritt Timber Supply Area (TSA) in south-central British Columbia (BC). There are five forested biogeoclimatic zones in the Merritt TSA (Forsite Consultants Ltd. 2010). A very small portion of the TSA is in the Coastal Western Hemlock zone (the wettest zone in $\mathrm{BC}$ ) and the Ponderosa Pine zone (the driest forested zone in BC). Most of the TSA is in the Engelmann Spruce Subalpine Fir zone (high elevations), the Montane Spruce zone, and the Interior Douglas-fir zone (a dry zone). These zones reflect the diverse topography of the region. Lodgepole pine is the predominant species in the TSA (Forsite Consultants Ltd. 2010).

The data are based on 37 sample trees from the Site Index - Biogeoclimatic Ecosystem Classification (SIBEC) project (B.C. Ministry of Forests and Range 2009). A typical SIBEC sample consists of two concentric plots on a site with a uniform ecosystem. The ecosystem is evaluated with a $10 \mathrm{~m}$ radius plot. A $5.64 \mathrm{~m}$ radius ( $0.01 \mathrm{ha}$ ) site index plot is centred in the ecosystem plot and one site tree of the target species is selected from within the site index plot. This plot size and number of trees were chosen because it meets the standards for site tree selection in BC. The site tree is the largest diameter tree in the plot of the target species and must be dominant or co-dominant, free of damage, suppression and other nonsite factors to ensure that the growth of the site tree reflects site productivity. The site tree is measured for height and breast height age. The sample trees were non-destructively sampled in 2013, 2014 and 2015. These sample trees were selected for this project because they were 30 years of age or less and this limits the results to younger trees. However, this is the age range where loss of growth has the greatest effect on site index and consequently is of primary interest.

The SIBEC sample trees were re-located late in the summer of 2015. Destructive sampling of the trees was done by felling the tree and removing the limbs. Crosscuts were made along the length of the stem from breast height $(1.3 \mathrm{~m})$ to the top of the tree (Fig. 1), through the pith but not all the way through the stem. This left the "lower side" of the stem intact, which made measuring the tree easier. Splitting wedges were

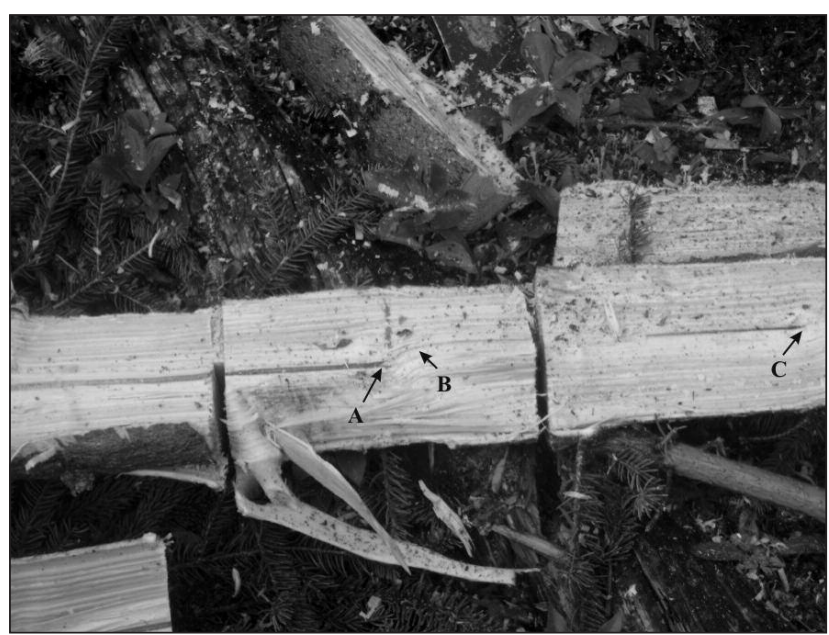

Fig. 1. Section of stem after splitting showing damage (note: this is not one of the sample trees from this project]. A node demarcating the beginning of growth in one year is at the centre of the photo (point A). The terminal bud or leader has been damaged and the lateral branch has taken over as the leader, as evidenced by the curve in the pith immediately after the node (point B). The node demarcating the end of growth for the year is found at the right of the photo (point C). 
Table 1. Summary of the extent of damage in the $\mathbf{3 7}$ sample trees

\begin{tabular}{cc}
\hline Number of incidences of damage & Number of trees \\
\hline 0 & 7 \\
1 & 12 \\
2 & 12 \\
3 & 5 \\
4 & 1 \\
\hline
\end{tabular}

used to knock off the "upper side" of the stem to reveal the inside of the tree, including the pith. Sharp knives were used to clear away any remaining wood that obscured the pith after splitting the stem. Pith nodes were identified and their height above breast height measured. Age (at breast height) is the node number above breast height. A careful inspection for leader damage was made and any node with damage was noted. Table 1 summarizes the extent of the damage. The 37 trees yielded 748 height growth observations.

Fig. 1 shows typical leader damage in a tree that has been split (note that this is not one of the sample trees from this project; it is for elucidation only). A node demarcating the end of growth in one year is at the centre of the photo. It is not readily apparent in the photo but is at the end of the darker part of the pith. The terminal bud or leader has been damaged and the lateral branch has taken over as the leader, as evidenced by the curve in the pith after the node. The node for the growth in the year in which the damage occurred is found at the right of the photo.

\section{Analysis}

Two hypotheses regarding how damage might affect height growth were proposed:

1) Hypothesis 1 (H1): Damage affects height growth in the year that the damage occurs and up to 2 subsequent years.

2) Hypothesis $2(\mathrm{H} 2)$ : Damage affects height growth in the year that it occurs and the effect accumulates with multiple damage events.

The null hypothesis in both cases was that damage does not affect height growth.

Plots of height growth versus age indicate that growth over the 0-30-year-age is nearly constant but some trees exhibit a linear or curvilinear growth pattern. Therefore a quadratic function of age was proposed as a base model for height growth. The parameters in this model were analyzed in a mixed-effects framework with tree as the subject to account for tree-to-tree variability in growth.

The fully-specified model for the two hypotheses is:

$$
\text { [1] } \begin{aligned}
\mathrm{Hg}_{\mathrm{ij}}= & {\left[\left(\beta_{0}+\mathrm{b}_{0 \mathrm{i}}\right)+\left(\beta_{1}+\mathrm{b}_{1 \mathrm{i}}\right) \times\left(\mathrm{A}_{\mathrm{ij}}+0.5\right)+\left(\beta_{2}+\mathrm{b}_{2 \mathrm{i}}\right) \times\right.} \\
& \left.\left(\mathrm{A}_{\mathrm{ij}}+0.5\right)^{2}\right] \times \mathrm{D}_{\mathrm{ij}}+\mathrm{e}_{\mathrm{ij}}
\end{aligned}
$$

Where $\mathrm{Hg}_{\mathrm{ij}}$ is the height growth $(\mathrm{m} / \mathrm{yr})$ of tree $\mathrm{i}(\mathrm{i}=1,2, \ldots$, 37) calculated as the increase in height from breast height age $A_{i j}$ to age $A_{i j+1}$ ( $j$ indexes the observation number within a tree); $\beta_{0}, \beta_{1}$, and $\beta_{2}$ are the fixed effect parameters; $b_{0 \mathrm{i}}, \mathrm{b}_{1 \mathrm{i}}$, and $b_{2 \mathrm{i}}$ are the random effect parameters and are assumed to be multivariate normally distributed with mean 0 and have an unstructured covariance matrix (Little et al. 2006) that is esti- mated from the data; $\mathrm{D}_{\mathrm{ij}}$ is a variable that tests the two hypotheses as described below and represents the average proportion of growth realized after damage as compared to the growth of an undamaged tree; and $\mathrm{e}_{\mathrm{ij}}$ is the random error term for tree $i$ at observation $j$. All fitting was done by maximum likelihood using procedure NLMIXED in SAS (SAS Institute Inc. 2011). Model fit was evaluated with Akaike's Information Criteria (AIC) (Burnham and Anderson 1988).

Data that are collected over time such as this data often have serial correlation in the random error term (Sen and Srivastava 1990). To account for this correlation, an AR (2) autocorrelation error structure was incorporated into the likelihood function using the fitting technique described by Harring and Blozis (2014). The AR (2) model assumes that $\mathrm{e}_{\mathrm{ij}}=\phi_{1} \times \mathrm{e}_{\mathrm{ij}-1}+\phi_{2} \times \mathrm{e}_{\mathrm{ij}-2}+\mathrm{a}_{\mathrm{ij}}$ where $\mathrm{a}_{\mathrm{ij}}$ are independently normally distributed errors with a mean of 0 (Seber and Wild 1989). The residuals from model [1] fitted under the assumption of no serial correlation were tested by tree for first-order serial autocorrelation with the Durbin-Watson statistic (Sen and Srivastava 1990). Twenty-six trees had no statistically significant autocorrelation in the residuals. For these trees, $\phi_{1}$ and $\phi_{2}$ were set to zero. For the remaining 11 trees, the autocorrelation parameters were estimated from the data with the 11 trees having a common estimate for both $\phi_{1}$ and $\phi_{2}$. The likelihood function for an AR (2) process from Seber and Wild (1989, pp. 286-288) was programed in place of the AR (1) structure presented in Harring and Blozis (2014). The variance of $\mathrm{a}_{\mathrm{ij}}$ (see AR (2) model definition above) is often assumed to be constant across all observations but a preliminary analysis showed that it varies considerably by tree. Consequently, the variance of $\mathrm{a}_{\mathrm{ij}}\left(\sigma_{\mathrm{a}_{\mathrm{i}}}^{2}\right)$ was allowed to vary by tree.

The two hypotheses are evaluated with the variable $\mathrm{D}_{\mathrm{ij}}$ as follows:

$\mathrm{H} 1: \mathrm{D}_{\mathrm{ij}}=\left\{\begin{array}{l}1 \text { if no damage is present at ages } \mathrm{A}_{\mathrm{ij}}, \mathrm{A}_{\mathrm{ij}}-1 \text {, and } \mathrm{A}_{\mathrm{ij}}-2 \text { on tree } \mathrm{i} \\ \mathrm{d}_{1} \text { if damage is present at age } \mathrm{A}_{\mathrm{ij}} \text { on tree } \mathrm{i} \\ \mathrm{d}_{2} \text { if damage is present at age } \mathrm{A}_{\mathrm{ij}}-1 \text { on tree } \mathrm{i} \\ \mathrm{d}_{3} \text { if damage is present at age } \mathrm{A}_{\mathrm{ij}}-2 \text { on tree } \mathrm{i}\end{array}\right.$

The $d_{i}, i=1,2$, or 3 , is the average proportion of height growth realized after a damage event at age $\mathrm{A}_{\mathrm{ij}}, \mathrm{A}_{\mathrm{ij}}-1$, or $\mathrm{A}_{\mathrm{ij}}$ - 2, respectively. In cases where damage occurred two or more years in a row, then precedence in selecting $\mathrm{D}_{\mathrm{ij}}$ is given to the most recent damage. For example, if damage occurred in the previous year and damage occurred again in the current year, $D_{i j}$ would take on the value of parameter $d_{1}$ as opposed to $\mathrm{d}_{2}$.

$$
\mathrm{H} 2: \mathrm{D}_{\mathrm{ij}}=\left\{\begin{array}{l}
1 \text { if no damage occurred between ages } \mathrm{A}_{\mathrm{i} 1} \text { and } \mathrm{A}_{\mathrm{ij}} \text { on tree } \mathrm{i} \\
\mathrm{d}_{1} \text { if damage occured once between ages } \mathrm{A}_{\mathrm{i} 1} \text { and } \mathrm{A}_{\mathrm{ij}} \text { on tree } \mathrm{i} \\
\mathrm{d}_{2} \text { if damage occured twice between ages } \mathrm{A}_{\mathrm{i} 1} \text { and } \mathrm{A}_{\mathrm{ij}} \text { on tree } \mathrm{i} \\
\mathrm{d}_{3} \text { if damage occured } 3 \text { times between ages } \mathrm{A}_{\mathrm{i} 1} \text { and } \mathrm{A}_{\mathrm{ij}} \text { on tree } \mathrm{i} \\
\mathrm{d}_{4} \text { if damage occured } 4 \text { times between ages } \mathrm{A}_{\mathrm{i} 1} \text { and } \mathrm{A}_{\mathrm{ij}} \text { on tree } \mathrm{i}
\end{array}\right.
$$

Parameters $\mathrm{d}_{1}, \mathrm{~d}_{2}, \mathrm{~d}_{3}$, and $\mathrm{d}_{4}$ represent the average proportion of growth realized after a damage event as compared to growth unaffected by damage. No tree had more than four incidents of damage; hence a test for the effect of five or more incidences was not necessary. Parameters that did not contribute to the fit of the model as evaluated by a reduction in the AIC were deleted from the model. 
The Pearson residuals from the fitted models (the $a_{i j}$ divided by the square root of the estimated variance of $\mathrm{Hg}_{\mathrm{ij}}$ ) were tested for bias and normality with a t-test and ShapiroWilk test (Shapiro and Wilk 1965), respectively. The Pearson residuals were also examined for normality with a q-q plot (Sen and Srivastava 1990) and for homoscedasticity with plots of residuals against tree age and predicted height growth.

\section{Results}

The AIC for the models that test the two hypotheses are - 1144 (H1) and -1054 (H2). Hypothesis 1 is clearly the most tenable hypothesis and only the results for this model are presented (Table 2). The parameter estimate for $\mathrm{d}_{3}$ did not contribute to the fit of this model $(\mathrm{AIC}=-1142$ when this parameter was
Table 2. Results of the analysis of the model for testing hypothesis 1

\begin{tabular}{ccc}
\hline \multicolumn{3}{c}{ Parameter } \\
\hline Name & Estimate & Standard error \\
\hline$\beta_{0}$ & 0.4068 & 0.01398 \\
$\beta_{1}$ & 0.007552 & 0.002251 \\
$\beta_{2}$ & -0.0002839 & 0.00008181 \\
$\sigma_{\mathrm{b}}^{2}$ & 0.004671 & 0.002477 \\
$\mathrm{~d}_{1}$ & 0.6509 & 0.02885 \\
$\mathrm{~d}_{2}$ & 0.8457 & 0.03032 \\
$\phi_{1}$ & 0.3835 & 0.07389 \\
$\phi_{2}$ & 0.2760 & 0.07856 \\
\hline
\end{tabular}

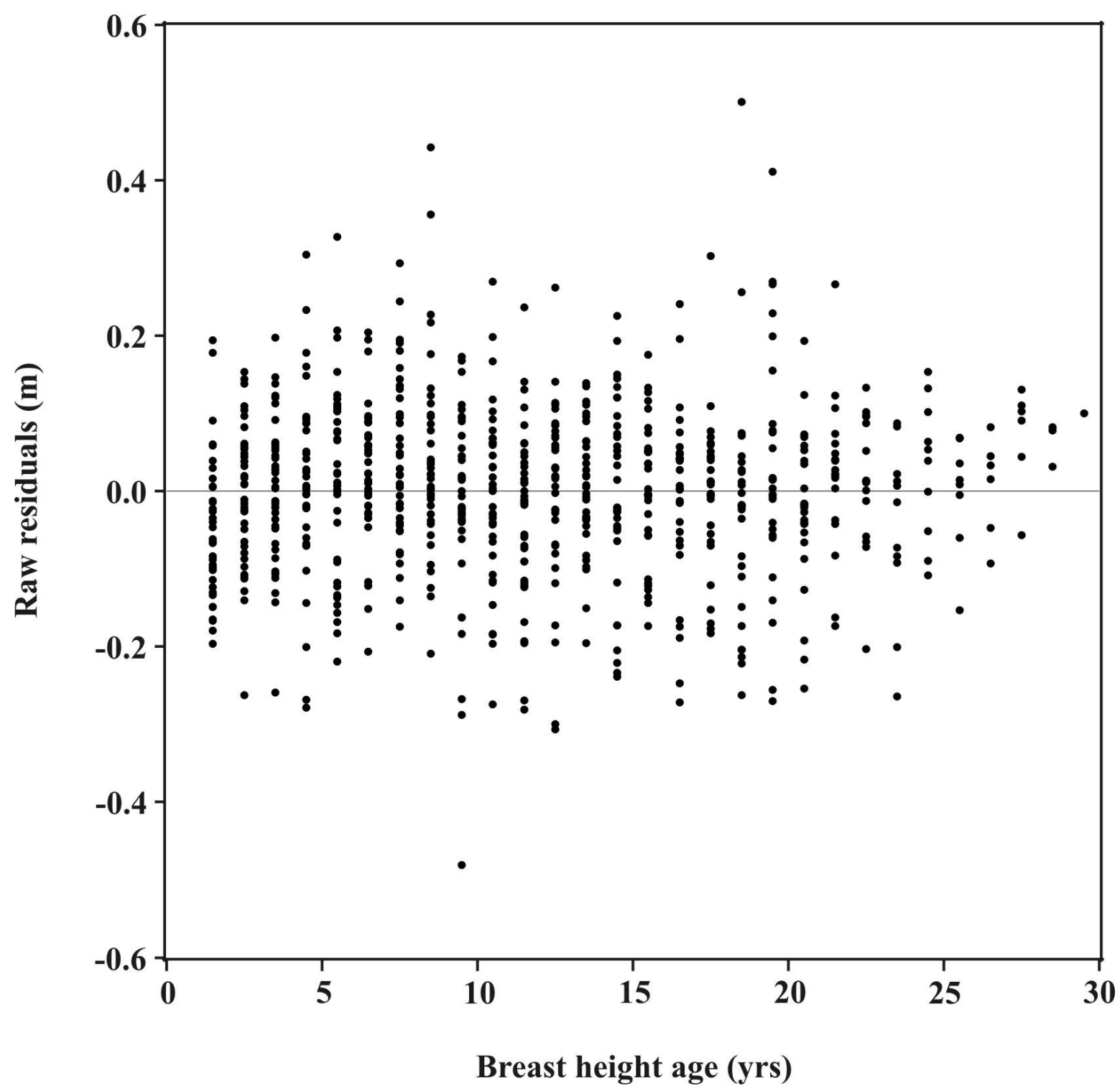

Fig. 2. Plot of the raw residuals against breast height age. 
included) and was not statistically significantly different from 1.0 at $\alpha=0.05\left(\mathrm{~d}_{3}=1.008\right.$ with a standard error of 0.033$)$. This indicates that growth returns to normal, i.e., $\mathrm{D}_{\mathrm{ij}}=1.0$, two years after the damage event. The estimates of $\sigma_{\mathrm{a}_{\mathrm{i}}}^{{ }^{1 j}}$ are not presented for brevity but ranged from 0.002075 to 0.03327 . Successful convergence of procedure NLMIXED could only be obtained with random effects parameter $b_{0}$ in the model. The mean of the Pearson residuals for this model was 0.017 with a standard error of 0.036 . The Shapiro-Wilk test for normality showed some evidence of non-normality $(p=0.04)$ but this test is very sensitive to non-normality with large numbers of observations, $\mathrm{n}=748$ for this analysis (Mason et al. 1989, $\mathrm{p}$. 534). The q-q plot did not show any significant departure from normality and the plots of the Pearson residuals against age and predicted height growth did not show any evidence of heteroscedasticity. Fig. 2 is a plot of the raw residuals (the $\mathrm{e}_{\mathrm{ij}}$ in equation [1]) against breast height age. There is no trend in the residuals which, along with the estimates of the residual variances $\sigma_{\mathrm{a}_{\mathrm{i}}}^{2}$, indicates that the fit is good.

To summarize, the fitted height growth model is:

$\mathrm{Hg}=\left[\left(0.4068+\mathrm{b}_{0}\right)+0.007552 \times(\mathrm{A}+0.5)-0.0002839 \times(\mathrm{A}+0.5)^{2}\right] \times \mathrm{D}$

Where $\mathrm{Hg}$ is the annual height growth $(\mathrm{m} / \mathrm{yr})$ at breast height age $\mathrm{A}, \mathrm{b}_{0}$ is a random effect parameter that must be predicted from available height growth and age data (e.g., Cao and Wang 2015), and

$\mathrm{D}=\left\{\begin{array}{l}1 \text { if no damage is present at age } \mathrm{A} \text { or } \mathrm{A}-1 \\ 0.6509 \text { if damage is present at age A } \\ 0.8457 \text { if damage is present at age A-1 }\end{array}\right.$

If damage is present at age $\mathrm{A}$ and at age $\mathrm{A}-1$, then the value for $\mathrm{D}$ corresponding to damage at age $\mathrm{A}$ is used in the model.

\section{Discussion}

The sampling protocols for this project called for selecting site trees less than 30 years at breast height as sample trees; therefore, the results apply to the population of lodgepole pine defined by the protocols. However, the results are likely applicable to trees which are not site trees. The results may not apply to trees with outwardly evident damage since this damage may be more severe than that encountered in this project. Older trees will likely have experienced more damage events.

Analysis shows that the effect of leader damage on height growth becomes negligible two years after the damage occurred. In the year that leader damage occurred, height growth was reduced by approximately $35 \%$. Leader damage resulted in a $15 \%$ decline in height growth in the year after the damage occurred. Stem splitting reveals that the damage is a result of the leader or terminal bud being damaged and a lateral branch becoming the leader. This damage is likely caused by abiotic factors such as frost (Hiratsuka and Zalasky 1993) or insects (Amman and Safranyik 1985). Since the sample trees were selected as being undamaged, based on a careful external examination of the tree when it was standing, the leader damage in these trees was rapidly overgrown and was not apparent from external examination. However, some damage in the upper stem of the taller trees may have been outwardly apparent but was obscured by foliage during the visual inspection from the ground. Unfortunately sampling protocols did not specify a check for this occurrence.
This research quantifies the effect of hidden leader damage on the height growth of site trees. This study and one by Nigh and Love (1999) show that damage in site trees is pervasive. One consequence of this is that lodgepole pine growth intercept and site index models were likely unintentionally developed with some trees that had experienced damage. If this is the case, then these models estimate the height growth of trees with varying and unknown amounts of leader damage. However, since these trees no longer exist, it is not possible to quantify any bias in site tree height growth and/or site index.

The amount and age at which damage occurs in a site tree and the age of the site tree on which the site index is based will affect the estimate of site index from that tree. Therefore, it is not possible to make general statements about the effect of damage on site index estimates. However, the following example demonstrates how an analyst may evaluate the effect of damage on a site index estimate. Suppose a lodgepole pine site tree faithfully tracks the height growth trajectory assumed by the growth intercept model (Nigh 1997); it would have a height of $5.9 \mathrm{~m}$ at age 10 , a height of $12.3 \mathrm{~m}$ at age 25 , and a height of $20 \mathrm{~m}$ at age 50, i.e., the site index is $20 \mathrm{~m}$. Now assume that the tree suffers damage at age 8 but after recovery grows without further damage until age 50 . Based on this research, the damage would result in a height growth loss of $0.24 \mathrm{~m}$ by age $10(0.17 \mathrm{~m}$ loss at age 8 and $0.07 \mathrm{~m}$ loss at age 9). Therefore, at age 50 , the height of the site tree will be 19.8 $\mathrm{m}$. However, if site index is estimated from the damaged tree at ages 10 and 25 using a height of 5.65 (5.89 minus 0.24 ) and 12.09 (12.33 minus 0.24$) \mathrm{m}$, respectively, the estimated site index is 19.41 and $19.69 \mathrm{~m}$. This is a bias of 0.59 and $0.31 \mathrm{~m}$ from the true site index (the height of the tree at age 50 if it had not been damaged), and a bias of 0.35 and $0.07 \mathrm{~m}$ from the height of the damaged tree at age 50 . The earlier and the more often damage occurs, the more bias there will be in the estimated site index. As trees age and accumulate more damage, the underestimation of site index will increase.

The results of this research reveal concerns with our ability to select site trees for site index estimation. Since site index is a measure of site productivity, the site trees used to estimate site index should be undamaged to avoid confounding site productivity with the effect of leader damage. However, leader damage becomes difficult to detect after radial growth has obscured the damage without destructively sampling the tree. The crux of the issue is that site trees exist but they are more difficult to identify than was previously thought. Approximately $80 \%$ of the sampled trees that were thought to be site trees based on outward appearances will be rejected after felling and splitting (from Table 1). Research in older stands may see this rejection rate approach $100 \%$ since leader damage is likely more prevalent in older trees. The costs of developing and applying growth intercept and site index models will increase because stem splitting will have to be done to properly identify site trees. Adding to the costs is the increased difficulty of finding good site trees due to the high rejection rates of potential site trees.

The following are some suggestions as to how to address the effects of site tree leader damage on site index estimates from growth intercept and site index models:

1) Accept that the site index estimates obtained from these models may underestimate the potential productivity of the site.

2) Adjust height to account for damage. This could involve 
developing an average correction factor to apply to all trees. Alternatively, if some outwardly identifiable tree characteristic that indicates leader damage could be found then it could be used to predict the amount of damage and make a correction to the height.

3) Base growth and yield predictions and forest management decisions on ecosystem type and/or site characteristics (for example see Green and Klinka 1994 and Boisvenue et al. 2004) and place less emphasis on site index as a decision variable.

\section{Conclusion}

Damage sustained by the leader of a tree can be concealed by radial growth over time, making past damage difficult to detect when selecting a tree as a site tree. This damage will result in a downward bias in site index. Leader damage results in a 35\% reduction (on average) in growth when damage occurs and height growth is reduced by $15 \%$ in the year after the damage event, after which normal height growth resumes. This research shows that finding undamaged site trees is harder than previously thought because it is not always possible to detect leader damage from an outward examination of a potential site tree. Estimating site index from damaged site trees will have an effect on the estimated site index.

\section{Acknowledgements}

Funding for the data collection was provided by the Land Based Investment of the British Columbia Ministry of Forests, Lands and Natural Resource Operations. I thank Peter Ott and Graham Hawkins of the British Columbia Ministry of Forests, Lands and Natural Resource Operations for review comments on an early draft. I thank the Associate Editor and reviewer for helpful comments that greatly improved the manuscript.

\section{References}

Amman, G.D. and L. Safranyik. 1985. Insects of lodgepole pine: Impacts and control. In: D.M. Baumgartner, R.G. Krebill, J.T. Arnott, and G.F. Weetman (eds.). Lodgepole Pine the Species and its Management - Symposium Proceedings, Spokane, Washington, 8-10 May 1984. pp. 107-124. Washington State University.

B.C. Ministry of Forests and Range. 2009. SIBEC sampling and data standards [online]. Available from http://www2.gov.bc.ca/ assets/gov/environment/research-monitoring-and-reporting/ research/research-documents/sibec-documents/standards.pdf [accessed 12 November 2015].

Boisvenue, C., H. Temesgen and P. Marshall. 2004. Selecting a small tree height growth model for mixed-species stands in the southern interior of British Columbia, Canada. For. Ecol. Manage. 202: 301-312.

Bontemps, J.-D. and O. Bouriaud. 2014. Predictive approaches to forest site productivity: Recent trends, challenges and future perspectives. For. 87: 109-128.

Burnham K.P. and D.R. Anderson. 1988. Model selection and inference: A practical information-theoretic approach. SpringerVerlag, New York, NY.

Cao, Q.V. and J. Wang. 2015. Evaluation of methods for calibrating a tree taper equation. For. Sci. 2: 213-219.
Carmean, W.H. 1975. Forest site quality evaluation in the United States. Adv. Agron. 27: 209-269.

Carvalho, J.P. and B.R. Parresol. 2005. A site model for Pyrenean oak (Quercus pyrenaica) stands using a dynamic algebraic difference equation. Can. J. For. Res. 35: 93-99.

Forsite Consultants Ltd. 2010. Timber supply analysis report [online]. Available from https://www.for.gov.bc.ca/hts/tsa/tsa18/ tsr2009/Merritt_TSR4_Analysis_Report.pdf [accessed 12 November 2015].

Green, R.N. and K. Klinka. 1994. A field guide to site identification and interpretation for the Vancouver Forest Region. Res. Br., B.C. Min. For., Victoria, B.C. Land Manage. Handb. No. 28.

Green, R.N., P.L. Marshall and K. Klinka. 1989. Estimating site index of Douglas-fir (Pseudotsuga menziesii [ Mirb.] Franco) from ecological variables in southwestern British Columbia. For. Sci. 35: $50-63$.

Harring, J.R. and S. Blozis. 2014. Fitting correlated residual error structures in nonlinear mixed-effects models using SAS PROC NLIMIXED. Behav. Res. Methods 46: 372-384.

Hiratsuka, Y and H. Zalasky. 1993. Frost and other climate-related damage of forest trees in the prairie provinces. Info. Rep. NOR-X331, Northern Forestry Centre, Edmonton, AB.

Krumland, B. and H. Eng. 2005. Site index systems for major young-growth forest and woodland species in northern California. California Dept. For. Fire Prot., California For. Rep. No. 4.

Littell, R.C., G.A. Milliken, W.W. Stroup, R.D. Wolfinger and O. Schabenberger. 2006. SAS for mixed models. $2^{\text {nd }}$ ed. Cary, NC.

Mason, R.L., R.F. Gunst and J.L. Hess. 1989. Statistical design and analysis of experiments with applications to engineering and science. John Wiley \& Sons, Toronto, ON.

Monserud, R.A. 1984. Problems with site index: An opinionated review. In: J.G. Bockheim (ed.). Proceedings of the Symposium Forest Land Classification: Experiences, Problems, Perspectives, Madison, Wisconsin, 18-20 March 1984. pp.167-180. USDA, For. Serv., North Central For. Exp. Sta., St. Paul MN Rep. NC-102.

Monserud, R.A. 1985. Applying height growth and site index curves for inland Douglas-fir. U.S.D.A. For. Serv., Res. Pap. INT-347. Nigh, G. D. 1997. Revised growth intercept models for lodgepole pine: Comparing northern and southern models. B.C. Min. For., Res. Br., Victoria, B.C. Ext. Note 11.

Nigh, G.D. and B.A. Love. 1999. How well can we select undamaged site trees for estimating site index? Can. J. For. Res. 29: 1989-1992.

Niklasson, M. 2002. A comparison of three age determination methods for suppressed Norway spruce: Implications for age structure analysis. For. Ecol. Manage. 161: 279-288.

Nord-Larsen, T. 2006. Developing dynamic site index curves for European Beech (Fagus sylvatica L.) in Denmark. For. Sci. 52: 173-181.

SAS Institute Inc. 2011. SAS OnlineDoc 9.3. Cary, NC: SAS Institute Inc.

Seber, G.A.F. and C.J. Wild. 1989. Nonlinear regression. John Wiley \& Sons, Toronto, ON.

Sen, A.K. and M. Srivastava. 1990. Regression analysis: Theory, methods, and applications. Springer-Verlag, New York, NY.

Shapiro, S. S. and M. B. Wilk. 1965. An analysis of variance test for normality (complete samples). Biometrika 52: 591-611.

Skovsgaard, J.P. and J.K. Vanclay. 2008. Forest site productivity: A review of the evolution of dendrometric concepts for even-aged stands. For. 81: 13-31. 